\title{
Liability Issues Concerning Self-Driving Vehicles
}

\begin{abstract}
Melinda Florina Lohmann*
This article deals with the civil liability issues that arise when self-driving vehicles are admitted to our streets. Firstly, it is explained why strict liability regimes for the vehicle holder, which are in place in several jurisdictions across Europe, are a workable foundation for ensuring compensation of the victim. However, accidents caused by highly automated vehicles will raise the question of the manufacturer's liability for a defective product. Accordingly, this article examines the effects of the circumstance that accidents occurring with selfdriving cars will no longer be caused by misconduct of the human driver, but often rather by a system malfunction. Thirdly, it is argued that preferably the manufacturer should be the risk bearer and that this shift in liability towards the manufacturer will result in an adequate allocation of liability.
\end{abstract}

\section{Introduction}

For decades self-driving cars were merely the subject matter of science fiction books and movies. Now these futuristic automobiles are on the verge of becoming reality. Already, Advanced Driver Assistance Systems such as anti-blocking systems, parking assist or lane keep assist systems are available on the market. The last step in the process of automation concerns fully automated or self-driving vehicles that

* Dr. iur. Melina Florina Lohmann was elected Assistant Professor of Business Law, with special emphasis on Information Law, at University of St. Gallen, as of August 12016 . For a comprehensive analysis of legal issues regarding automated vehicles see Melinda Florina Lohmann, Automatisierte Fahrzeuge im Lichte des Schweizer Zulassungs- und Haftungsrechts (Baden-Baden: Nomos 2016).

1 UK Department for Transport, The Pathway to Driverless Cars (London: DfT Publications, 2015), at p. 18.

2 Lennart S. Lutz, "Anforderungen an Fahrerassistenzsysteme nach überstaatlichem Recht", in Eric Hilgendorf and Sven Hötitzsch (eds.), Das Recht vor den Herausforderungen der modernen Technik (Baden-Baden: Nomos, 2015), pp. 171 et sqq., at p. 171

3 Tom M. Gasser, "Legal Issues of Driver Assistance Systems and Autonomous Driving", in Azim Eskandarian (ed.), Handbook of Intelligent Vehicles (London: Springer, 2012), pp. 1520 et sqq., at p. 1520 .

4 UK Department for Transport, Pathway, supra note 1, at p. 14

5 UK Department for Transport, Pathway, supra note 1, at p. 13.

6 For an analysis of the use of anthropological vocabulary in regard to machines: Melinda Florina Müller, "Von vermenschlichten Maschinen und maschinisierten Menschen", in Sandra Brändli/Rehana Harasgama/Roman Schister/Aurelia Tamò (eds.) Mensch und Maschine - Symbiose oder Parasitismus (Bern: Stämpfli Verlag, 2015), pp. 595 et sqq. no longer require a driver. These vehicles are "designed to be capable of safely completing journeys without the need for a driver in all normally encountered traffic, road and weather conditions."1 In fact, car manufacturers have announced the market launch of fully automated vehicles for $2020 .^{2}$

The implementation of fully automated vehicles is possible due to highly sophisticated hardware and software, especially due to improved sensors and data interpretation mechanisms. The introduction of self-driving cars promises an increase of safety in road traffic by taking the most accident-prone factor out of the loop, the human driver. ${ }^{3}$ In turn, the driver and his passengers benefit from improved comfort. Not having to constantly pay attention to traffic allows for free time to read the newspapers, answer emails or simply relax. Moreover, automated vehicles will make driving easier and offer greater mobility to a wider range of people than ever before. ${ }^{4}$ In addition, self-driving cars are expected to increase ecological efficiency by regulating fuel use and planning travels in an environmentally friendly manner. ${ }^{5}$ This of course will at the same time benefit economic efficiency.

Of course, not every person will be eager to hand over the task of driving to a machine. Some may enjoy driving as such and will not want to miss out on this experience. Others may be concerned about the vulnerabilities of self-driving cars and reluctant to place their lives in the "hands" of a machine. ${ }^{6}$ In fact, a researcher has recently figured out how to hack a self-driving car's sensors and disturb its perfor- 
mance. ${ }^{7}$ Apart from concerns regarding the car's hackability, security issues will predominantly concern software bugs as systems will never be 100\% safe. ${ }^{8}$ Users will be especially sensitive to accidents caused by a technical failure, as people tend to have strong emotional reactions "against a safety innovation that actually causes harm, even if the net effect of the innovation is to improve safety." ${ }^{\prime \prime}$ Accordingly, if a system's malfunction causes a traffic accident, questions of liability will arise.

This article addresses the issue of civil liability concerning self-driving vehicles. ${ }^{10}$ Specifically, three propositions shall be made: Generally, under strict liability regimes in place across Europe the vehicle holder will remain liable for accidents caused by automated vehicles (II.ı.). Yet, with increased vehicle automation a shift in liability from the vehicle holder to the vehicle manufacturer will occur (II.2.). This shift in liability and the allocation of risk is deemed acceptable as the manufacturer proves to be the adequate risk bearer (II.3.).

\section{A Change in the Dynamics of Liability}

\section{Strict Liability of the Automated Vehicle Licence Holder}

The regulation of road traffic liability differs for every country and would have to be analysed individually. However, in this article some generalized findings

7 Mark Harris, "Researcher Hacks Self-driving Car Sensors", 4 September 2015, available on the Internet at «http://spectrum ieee.org/cars-that-think/transportation/self-driving/researcher -hacks-selfdriving-car-sensors?utm_campaign=Weekly \%20Notification-\%20IEEE\%20Spectrum\%20Tech\%20Alert\&utm source=boomtrain\&utm_medium $=$ email \&utm_content $=\& b t$ _alias

=eyJ1c2VySWQiOijjNDRhMWZIOS1 hNmNhLTQ1NmItODg4Y S03M2Q1NDk3Y2RhZmMifQ\%3D\%3D (last accessed on 7 October 2015)

8 Curtis E.A. Karnow, "Liability for Distributed Artificial Intelligences", 11 Berkeley Tech. L.J. (1996), pp. 147 et sqq., pp. 162 et sqq.

9 Gary E. Marchant and Rachel A. Lindor, "The Coming Collision between Autonomous Vehicles and the Liability System", 52 Santa Clara L. Rev. (2012), pp. 1321 et sqq., at p. 1335; Jack Boeglin, "The Costs of Self-Driving Cars", 17 Yale J.L. \& Tech. (2015), pp. 171 et sqq., at p. 188; Robolaw, "Regulating Emerging Robotic Technologies in Europe, Guidelines on Regulating Robotics", 22 September 2014, available on the Internet at «ttp://www .robolaw.eu/RoboLaw files/documents/robolaw d6.2 _guidelinesregulatingrobotics_20140922.pdf (last accessed on 7 October 2015), at p. 58. can be made on the basis that most European countries have implemented a regime of strict liability for the holder of the license to the vehicle, i.e. liability for traffic accidents regardless of fault. ${ }^{11}$ The "hold$\mathrm{er}^{\prime \prime 12}$ is defined as the person who uses the vehicle at his own expense. ${ }^{13}$ Consequently, he is liable for all damage caused due to the operational risk. ${ }^{14}$ This operational risk also encompasses the risk of automation. ${ }^{15}$ It can include wrong handling of the automatic system by the driver as well as technical defects of the system leading to an accident. Hence, accidents caused with self-driving vehicles (and thus the realisation of their operational risk) are covered by the strict liability of the vehicle holder. In summary, the strict liability regimes in place in most European countries adequately cover the liability of the vehicle holder for accidents caused with automated vehicles.

In some jurisdictions the liability of the driver, who is not simultaneously the vehicle holder, is faultbased, as opposed to the strict liability of the vehicle holder. ${ }^{16}$ Such fault-based liability prompts several questions in the context of vehicle automation, e.g. how to qualify mechanic actions and who to blame for the self-driving car's decisions. With fully automated vehicles the driver's attention is dispensable in the automated driving phase. ${ }^{17}$ Consequently, it would seem contradictory to assume negligence of the driver if an accident occurred during such an automated phase. ${ }^{18}$ The introduction of fully automated cars might lead to a transition in the underlying understanding that only a human can be responsible

10 On criminal responsibility: Melinda Florina Lohmann/Arnold Rusch, "Fahrassistenzsysteme und selbstfahrende Fahrzeuge im Lichte von Haftpflicht und Versicherung", 4 HAVE (2015), pp. 349 et $s q q .$, p. 350.

11 Gasser, Legal Issues, supra note 3, at p. 1528; see overview in Robolaw, Guidelines, supra note 9, at p. 64.

12 So called "Halter" under Swiss and German law, see Art. 58 para. 1 of the Swiss Road Traffic Act, $\S 7$ para. 1 of the German Road Traffic Act.

13 Gasser, Legal Issues, supra note 3, at p. 1529.

14 Gasser, Legal Issues, supra note 3, at p. 1529.

15 Gasser, Legal Issues, supra note 3, at p. 1529.

16 This is the case under Swiss law (Art. 41 para. 1 of the Swiss Code of Obligations). In the UK, the liability of the driver is fault-based; in Sweden the costs of traffic accidents are rather covered by first party insurance (Robolaw, Guidelines, supra note 9, at p. 64). In Germany the driver is assumed to be at fault, unless he can prove otherwise (Gasser, Legal Issues, supra note 3, at p. 1529).

17 Gasser, Legal Issues, supra note 3, at p. 1529.

18 Gasser, Legal Issues, supra note 3, at p. 1529. 
for his harmful actions. This traditional understanding is further tested in the event that self-driving cars are equipped with "an expert system that will gain knowledge and skills from its own 'decisions', while learning from the features of the environment and from the living beings who inhabit it." ${ }^{19}$ In this case, the adequate attribution of responsibility becomes an even more challenging task. ${ }^{20}$

However, de facto, in the context of traffic accidents, these questions are not pivotal under most European traffic law regimes with strict liability schemes in place. In these regimes, the injured party will primarily proceed against the vehicle holder (or against the insurance company based on the mandatory insurance contract ${ }^{21}$ ) on the grounds of the holder's strict liability rather than the driver's fault-based liability. Then the question of who was driving - man or machine - is not relevant. Thus, in an automated context, taking action against the vehicle holder or preferably taking (direct) action against the insurer seems the easiest and safest way for the victim to claim damages. Yet, the liability of the vehicle holder may not cover all damages: If for example, the holder himself is hurt when driving his car, this damage is not covered. ${ }^{22}$ In any event, a further potentially liable party exists: the manufactur-

19 Ugo Pagallo, "Guns, Ships, and Chauffeurs: The Civilian Use of UV Technology and its Impact on Legal Systems", 21 J.L. Inf. \& Sci. (2011), pp. 224 et sqq., at p. 231.

20 Pagallo, Guns, supra note 19, pp. 231 et sqq.; Melinda Florina Müller, "Roboter und Recht: Eine Einführung", 5 Aktuelle Juristische Praxis (2014), pp. 595 et sqq., pp. 598 et sqq.; Boeglin, Costs, supra note 9 , at p. 175

21 See e.g. Art. 65 para. 1 of the Swiss Road Traffic Act.

22 He may however have first party insurance (Robolaw, Guidelines, supra note 9 , at p. 66).

23 Marchant and Lindor, Collision, supra note 9, at p. 1326; Ronald Leenes and Federica Lucivero, "Laws on Robots, Laws by Robots, Laws in Robots: Regulating Robot Behaviour by Design", 6(2) LIT (2014), pp. 193 et sqq., at p. 207; Robolaw, Guidelines, supra note 9 , at p. 58 .

24 Boeglin, Costs, supra note 9, at p. 185; Marchant and Lindor, Collision, supra note 9, at p. 1328.

25 M. Ryan Calo, "Open Robotics", 70 Md. L. Rev. (2011), pp. 571 et sqq., at p. 597.

26 The seller of the vehicle may be liable for defects under contract law.

27 Switzerland has implemented the Directive with its Product Liability Act.

28 Gasser, Legal Issues, supra note 3, at p. 1532.

29 Wolf Günther, „Nutzungsrechte und Haftungsvermeidung", 8 Elektronik automotive (2006), pp. 52 et sqq., at p. 52; see Karnow, Liability, supra note 8, at p. 162. er. The importance of the manufacturer in the scheme of liability for self-driving vehicles will be discussed in the following section.

\section{Shift in Liability Towards the Manufacturer}

While the total number of accidents is likely to decrease, a notable shift in responsibility towards the manufacturer is to be expected..$^{23}$ Nowadays, only a small fraction of accidents is caused by technical defects. And of these technical defects, a great portion is attributable to poor maintenance of the car by the vehicle holder, so that he may again be allocated some or all of the blame for a resulting crash. However, in the future, car crashes caused by automated vehicles will rather be attributable to a product defect, as the (mis-)conduct of the driver will no longer be a relevant accident cause. Programming errors or system failures will cause malfunctions of automated vehicles, hence potentially implicating several parties who may be held liable. ${ }^{24}$ Of course in practice, detecting a defect and proving it in court will be challenging for the injured party. ${ }^{25}$

The vehicle (and component) manufacturer is bound by product liability law for defects regarding design, construction and instruction. ${ }^{26}$ The EU Directive $85 / 374 /$ EWG on product liability has introduced a regime of strict liability to member states of the EU. ${ }^{27}$ According to Article 1 of the EU Directive the manufacturer shall be liable for damage caused by a defect in his product. A product is defective when it does not provide the safety, which a person is entitled to expect, taking all circumstances into account (Article 6). With regard to highly safety-critical automated vehicles these expectations will be particularly intense. ${ }^{28}$ For automated driving systems a safe design will be of utmost importance. Indeed, even a careful design of automated driving systems cannot fully eliminate the unreliability of software. ${ }^{29}$ However, regardless of this inherent unreliability a person is entitled to expect a safe product and can consequently hold the vehicle 's manufacturer responsible for a crash caused due to a software bug in the automated system. The manufacturer can minimize his liability exposure by satisfying state of the art when designing his product and monitoring it by regular software updates and bug fixes. In this regard, safety standards for automated vehicles will be es- 
sential. ${ }^{30}$ In particular, car manufacturers will have to implement extensive testing procedures in order to maximize safety.

The instruction of the user by the manufacturer is important, especially so, if the car's actions can be oversteered by the human driver. For this system design the user must know precisely what is expected of him. However, it will be impossible for the manufacturer to anticipate all possible scenarios the selfdriving vehicle will encounter and instruct the user accordingly, especially for a technology as complex as fully automated driving systems. ${ }^{31}$ And if cars are fitted with self-learning expert systems, as Pagallo notes ${ }^{32}$ a further dimension of uncertainty is added. While the manufacturer will try to design the car and instruct the user in a way as to minimize the risk of an accident, a high risk of liability will remain. ${ }^{33}$ Ironically, even though automated cars are deemed safer overall than manually driven cars, the manufacturer's liability exposure will likely be greater. ${ }^{34}$ This effect may well be detrimental to innovation. In the next section, the societal impact of the expected liability exposure will be analysed. To this end, some thoughts about the optimal allocation of costs must be made.

\section{Manufacturer as the Adequate Risk Bearer}

Liability law serves the two main purposes of compensation and deterrence, that is, protecting the injured party by ensuring compensation and providing incentives for the "responsible" person to take adequate measures to prevent the occurrence of damage. ${ }^{35}$ Let us now examine whether adequate incentives are given and compensation is ensured in the case of automated vehicles.

The possibility of taking action against the vehicle holder and especially against the insurer allows for compensation of the victim. From the point of view of the victim, e.g. a pedestrian hit by a self-driving car, his interests do not change due to the mere fact that the vehicle operated automatically. Thus, a system of strict liability of the vehicle holder for damage caused by the operation of his vehicle, paired with mandatory insurance and a direct legal claim of the victim against the insurer, is advisable. It seems fair to burden the vehicle holder with the risk of automation, as he is the person who decides to introduce an automated vehicle into traffic and can take certain measures to ensure a safe functioning, e.g. undertake system checks before use. Moreover, the holder is the person profiting from the use of a self-driving car. ${ }^{36}$ In any case, the operational risk of a self-driving car is expected to be a lot lower than that of a manually driven car, so that the holder will benefit from a diminished accident risk. However, the holder or more often his insurer must be allowed to take recourse against the manufacturer or else liability law's incentive function can no longer take effect. ${ }^{37}$

The vehicle manufacturer is the adequate risk bearer. ${ }^{38}$ It is desirable to incentivise the manufacturer to make incremental improvements in safety design. ${ }^{39}$ Even though the vehicle keeper can take some measures to reduce the risk of malfunction of the vehicle, it is chiefly the manufacturer who can influence product safety through diligent design and construction and who can instruct the user about the product's risks. ${ }^{40}$ Manufacturers profit from the business of selling automated vehicles and can transfer some of the costs back to consumers through higher vehicle prices. ${ }^{41}$

A predominant concern against the manufacturer's exposure to liability is that the expected shift in liability towards the manufacturer might pose a disincentive for manufacturers to produce automated vehicles. ${ }^{42}$ In view of the overall benefits of vehicle automation for road safety, the production of auto-

30 See Stephen S. Wu, "Product Liability Issues in the U.S. and Associated Risk Management", in Markus Maurer and J. Christian Gerdes and Barbara Lenz and Hermann Winner (eds.), Autonomes Fahren (Heidelberg: Springer Verlag, 2015), pp. 575 et sqq., at p. 589.

31 Marchant and Lindor, Collision, supra note 9, at p. 1333.

32 Pagallo, Guns, supra note 19, at p. 231.

33 Marchant and Lindor, Collision, supra note 9, at p. 1334.

34 Marchant and Lindor, Collision, supra note 9, at p. 1339.

35 Arthur Best and David W. Barnes and Nicholas Kahn-Fogel, Basic Tort Law, 4th ed. (New York: Wolters Kluwer, 2014), at p. 8; Robolaw, Guidelines, supra note 9, at p. 55.

36 Lohmann and Rusch, Fahrerassistenzsysteme, supra note 10, at p. 352.

37 Robolaw, Guidelines, supra note 9, at p. 63.

38 Lohmann and Rusch, Fahrerassistenzsysteme, supra note 10, at pp. 352.

39 Marchant and Lindor, Collision, supra note 9, at p. 1340.

40 Robolaw, Guidelines, supra note 9, at p. 63.

41 See Marchant and Lindor, Collision, supra note 9, at p. 1336.

42 Leenes and Lucivero, Laws, supra note 23, at p. 207; Robolaw, Guidelines, supra note 9, at p. 56; Marchant and Lindor, Collision, supra note 9 , at p. 1334. 
mated vehicles seems socially desirable. ${ }^{43}$ Manufacturers must make a business decision whether or not to invest in this type of vehicle innovation. If they do so, it is their duty to provide the expected safety, or else they will be faced with claims. The possibility of recourse against the manufacturer does not impede him from escaping liability if he proves that he was not able to detect the defect in conformity with state of the art at the time of placing his product on the market. ${ }^{44}$

All in all, the injured party must be able to take action against the vehicle holder or his mandatory insurance. In turn, the vehicle holder or his insurance may want to take recourse against the manufacturer based on product liability. As long as this course of action is open to the parties, this solution strikes a fair balance between the involved parties and sets the right incentives for achieving a socially optimal outcome. ${ }^{45}$ Alternatively - rather than working with a liability scheme - the Swedish insurance model could serve as a starting point: Accordingly, the victim of a traffic accident is compensated by first party insurance, ${ }^{46}$ that is, insurance against damage, and not liability. ${ }^{47}$ It has been suggested to place Sweden's insurance model on top of existing liability schemes and make a Sweden-type first-party insurance mandatory for automated cars. ${ }^{48}$ However, this approach has several drawbacks. For example, since the system is not based on liability, the deterrence function of liability law is set aside. ${ }^{49}$ Moreover, the system may be more expensive, since claiming compensation is facilitated. ${ }^{50}$ In any event, further research is necessary to analyse the advantages and dis-

\footnotetext{
43 Robolaw, Guidelines, supra note 9, at p. 59.

44 Robolaw, Guidelines, supra note 9, at p. 58.

45 Marchant and Lindor, Collision, supra note 9, at p. 1334

46 I.e., one's own insurance company pays one's own damages (Leenes and Lucivero, Laws, supra note 23, at p. 207).

47 Robolaw, Guidelines, supra note 9, at p. 64.

48 Leenes and Lucivero, Laws, supra note 23, at p. 207; Robolaw, Guidelines, supra note 9, at p. 65

49 On the other hand, higher insurance premiums may somewhat fulfil this purpose (Robolaw, Guidelines, supra note 9, at p. 65).

50 On the other hand, legal expenses will also be reduced, Robolaw, Guidelines, supra note 9, at p. 65.

51 Gasser, Legal Issues, supra note 3, at p. 1529.

52 Müller, Roboter, supra note 20, pp. 605 et sqq.

53 Gasser, Legal Issues, supra note 3, pp. 1532 et sqq.

54 UK Department for Transport, Pathway, supra note 1, at p. 6.

55 Robolaw, Guidelines, supra note 9, at p. 63
}

advantages of such an insurance scheme. At this stage of technological development it is advisable for legislators across Europe to reflect on different possibilities to deal with accidents caused by self-driving cars.

Furthermore, a closely related issue, namely that of Event Data Recorders (EDR) and their use, must be discussed. EDRs will certainly play a crucial role in providing evidence in a trial and proving the accident occurrence and its cause. ${ }^{51}$ At the same time, the installation of EDRs is highly critical in the light of data privacy law as well as criminal law and its principle that there is no legal obligation to self-incriminate oneself (nemo tenetur principle). ${ }^{52}$ In general, data protection and privacy issues will play an important role in the development and customization of self-driving cars, as fully automated vehicles depend on the collection of (sensitive) data. These aspects are to be considered at an early stage in the development of such systems. ${ }^{53}$

\section{Conclusion}

Self-driving vehicles potentially offer major benefits in regard to road safety, social inclusion, reduction of emissions, and avoidance of congestion. ${ }^{54}$ The admittance of self-driving cars will inevitably raise questions of liability. In terms of product liability, manufacturers of safety-critical automated vehicles will need to fulfil high safety standards to avoid liability. In fact, manufacturers might soon be facing damage claims for a higher proportion of accidents than today, as accidents might be traced back to a product defect in a large number of cases. This article discussed the resulting shift in liability from the vehicle holder to the vehicle manufacturer. In order to adequately allocate the risk of this innovation, a liability system is required in which the manufacturer is neither overexposed to liability, as this would discourage production, nor is underexposed to liability, as this would undermine the purpose of liability law, namely the prevention of accidents and the compensation of victims. ${ }^{55}$

Under the regimes of several European countries a workable solution is already in place, with the vehicle holder being strictly liable for the operational risk, including that of automation. Compensation of the victim is ensured by the possibility of taking action against the holder of the self-driving car or preferably against his mandatory insurer. Further, an 
effective incentive scheme requires insurers to be able to take recourse against the vehicle manufacturer in case the automated vehicle that caused the accident was indeed defective. In any event, this scheme satisfies the two main purposes of liability law and could function as a basic framework for the launch of automated vehicles - which is just around the corner. 


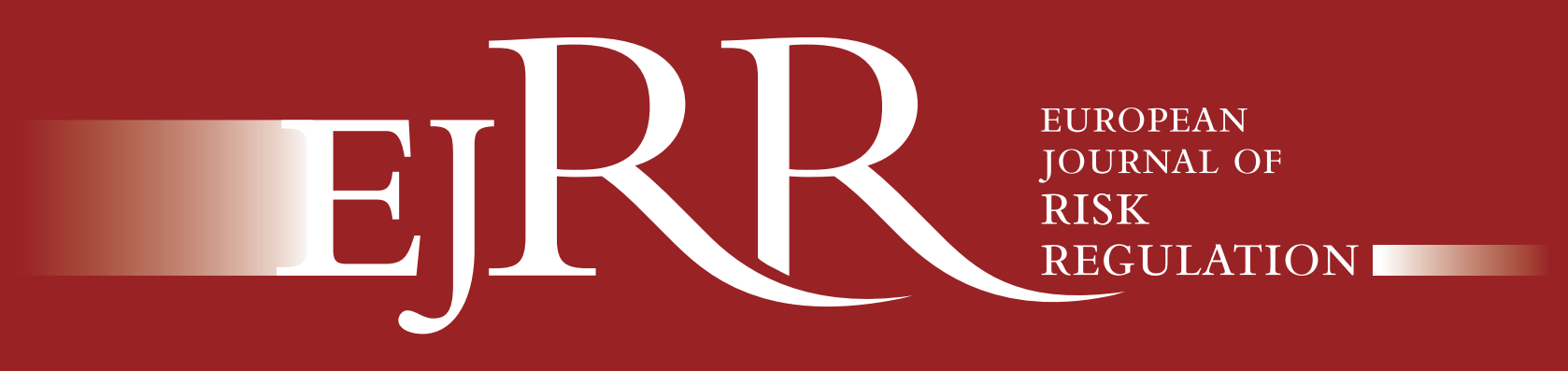

SYMPOSIUM ON TTIP LEAKS

Editors: Alberto Alemanno and Alexia Herwig

Contributors: Alberto Alemanno, Ronny Patz, Vigjilenca Abazi, Christian Häberli, Alan Matthews, Alexia Herwig, Benjamin Farrand, Bart Van Vooren, Charlotte Ryckman, Marco

Rizzi, Sara Pugliese, Ferdi De Ville, Jan Orbie and Lore Van den Putte

\section{SPECIAL ISSUE ON THE MAN AND THE MACHINE}

Editors: Thomas Burri and Isabelle Wildhaber

Contributors: Thomas Burri, Isabelle Wildhaber, Shaw Bayern, Madeleine de Cock Buning, Ugo Pagallo, Massimo Durante, and Melinda Florina Lohmann

\section{ARTICLES}

Regulatory Intervention beyond the Law Aute Kasdorp

A(nother) Plea for Reform to EU Standing Rules Michael Rhimes

The Use of Evaluative Information in Impact Assessments and Ex-post Evaluations in the EU

Thomas van Golen and Stijn van Voorst

\section{REPORTS}

International Investment Agreements as a New and More Legitimate Way to Manage Risks

Azernoosh Bazrafkan and Alexia Herwig

The EU's Unlawful Pesticide Approval Practice

Anne de Vries-Stotijn

\section{CASE NOTES}

Continuing Road Back Home as Protected Indications of Geographical Origin

Vadim Mantrov

Patenting Isolated Nucleic Acids

Emanuela Gambini 


\section{Contents}

Editorial

SYMPOSIUM ON TTIP LEAKS

What the TTIP Leaks Mean for the On-going Negotiations and Future

Agreement?

Time to Overcome TTIP's many Informational Asymmetries

Alberto Alemanno

Just the TTIP of the Iceberg? Dynamics and Effects of Information Leaks in EU

Politics

Ronny Patz

How Confidential Negotiations of the TTIP Affect Public Trust

Vigjilenca Abazi

TTIP Leaks: A Welcome Opportunity for More Homework

Christian Häberli

Food Safety Regulation in TTIP: Much Ado About Nothing?

Alan Matthews

TTIP Regulatory Cooperation

Changes in Transnational Risk Regulation from WTO Law and WTO-Consistency

Alexia Herwig

Two Continents, Divided by Deep Philosophical Waters?

Why Geographical Indications Pose a Challenge to the Completion of the TTIP

Benjamin Farrand

TTIP as a Platform for Progress in Pharma and Medtech Regulations

Bart Van Vooren and Charlotte Ryckman

Thoughts on Transatlantic Regulatory Cooperation in Pharmaceuticals after \#TTIPleaks

Marco Rizzi

Divergences between EU and US in the Financial Regulation

What Effects on the TTIP Negotiations?

Sara Pugliese

Sustainable Development in TTIP: A Highest Common Denominator

Compromise?

Ferdi De Ville, Jan Orbie and Lore Van den Putte

\section{SPECIAL ISSUE ON THE MAN AND THE MACHINE}

Introduction to the Special Issue on the Man and the Machine

Thomas Burri and Isabelle Wildhaber

The Implications of Modern Business-Entity Law for the Regulation of

Autonomous Systems

Shawn Bayern

Autonomous Intelligent Systems as Creative Agents under the EU framework for Intellectual Property

Madeleine de Cock Buning 
The Pros and Cons of Legal Automation and its Governance

Ugo Pagallo and Massimo Durante

Liability Issues Concerning Self-Driving Vehicles

Melinda Florina Lohmann

The Politics of Robot Autonomy

Thomas Burri

\section{ARTICLES}

Regulatory Intervention beyond the Law

Towards a Typology of the Extra-Legal Frontier

Aute Kasdorp

Nothing Ado About Much?

Challenges to Anti-Dumping Measures After the Lisbon Reforms to Art 263(4) TFEU

Michael Rhimes

Towards a Regulatory Cycle? The Use of Evaluative Information in Impact

Assessments and Ex-post Evaluations in the European Union

Thomas van Golen and Stijn van Voorst

Protection without Discrimination: Pregnancy and Occupational Health

Regulations

Sven Hove Hansson and Linda Schenk

\section{REPORTS}

\section{Biotechnology}

The European Ombudsman Urges the European Commission to Abandon its Unlawful Pesticide Approval Practice

Anne de Vries-Stotijn

Food

Geographical indications, "Food Fraud" and the Fight Against "Italian sounding" Products

Ignacio Carreño and Paolo R. Vergano

The Global Combat Against IUU Fishing: The United States Proposes a New

Seafood Traceability Program

Bruno G. Simões and Tobias Dolle

Pharmaceuticals

Promoting the Off-label Use of Medicines: Where to Draw the Line?

Genevra Forwood and James Killick

\section{Regulatory Impact Assessments}

The "Eco-leather" Claim: The Urgent Need for a Mandatory Labelling System for Leather Products at EU Level

Alessandra Fratini and Mariacristina Bottino

Trade, Investment and Risk

Reinterpreting the Fair and Equitable Treatment Provision in International Investment Agreements as a New and More Legitimate Way to Manage Risks Azernoosh Bazrafkan and Alexia Herwig 


\section{CASE NOTES}

The Cases of Edam Holland and Gouda Holland: Continuing Road Back Home as Protected Indications of Geographical Origin Vadim Mantrov

In the Aftermath of $D^{\prime}$ Arcy v. Myriad Genetics Inc: Patenting Isolated Nucleic Acids in Australia

Emanuela Gambini

\section{BOOK REVIEWS}

The Black Box Society: The Secret Algorithms That Control Money and

Information, by Frank Pasquale, Harvard University Press, 2015

Sofia Ranchordás

Exposed: Desire and Disobedience in the Digital Age, by Bernard E.

Harcourt, Harvard University Press, 2015

Tsung-Ling Lee

\section{MISCELLANEOUS}

Masthead

Imprint 